There is a pressing need to establish relay stations between clinical and basic research. Psychiatry is a good example. Today we are treating our patients with antidepressant drugs that were discovered 40 years ago and that are far from satisfactory. We still do not know precisely what mechanism of action causes their beneficial effect. This is surprising if one considers the progress in basic neurobiology that has not yet led to major therapeutic consequences.

Today clinical research is threatened because the public is no longer willing to accept the rapidly growing cost of medical care. Tomorrow it will be the basic sciences that run out of money because the public will ask questions about the benefits. Both the clinical and the basic sciences will defuse these threats if they rethink their attitudes and accept that basic research must, at least to a large extent, serve clinical research. Future preclinical research must focus on observations by the physician-scientist in order to justify funding, and future clinical research must design studies that lead to data that can be consolidated in basic research experiments.

If this goal is achieved both will profit: basic laboratory science will be able to demonstrate its direct impact on clinical practice and clinical investigations will continue to be essential to provide input for basic research.

The first issues of Nature Medicine are extremely promising as a venue for fostering the necessary dialogue.

\section{FLORIAN HOLSBOER}

Max-Planck-Institut fur Psychiatrie

Klinisches Institut

80804 Munich, Germany

\section{The PKD1 gene product}

To the editor - We would like to bring to your attention a report ${ }^{1}$ that has significant implications for an autosomal dominant polycystic kidney disease study that was reported in the April issue of Nature Medicine ${ }^{2}$. This study described the characterization and localization of an extracellular matrix protein using antibodies raised against a decapeptide from the predicted extreme $\mathrm{COOH}$ terminal domain of the PKD1 gene product $^{3}$. The American Polycystic Kidney
Disease Consortium has identified an important difference between their sequence and that previously published; a two-base pair insertion results in the replacement of the originally predicted 92 $\mathrm{COOH}$-terminal residues with 12 novel residues. This sequence difference has been found in two cloned genomic templates and one cDNA template and has been confirmed using allele-specific oligonucleotides and PCR products derived from the genomic DNA of nine individuals. The European Polycystic Kidney Disease Consortium has also re-analysed the original sequence and confirmed the presence of the two-base pair insertion. We therefore conclude that there are currently no data supporting the presence of the originally published $\mathrm{COOH}$ terminal peptide sequence within the final PKD1 gene product. It is clear, therefore, that the relationship between the PKD1 gene product to the extracellular matrix protein identified with these anti-peptide antibodies ${ }^{2}$ is uncertain and should be viewed with caution.

Peter C. HARris

Molecular Haematology Unit

Institute of Molecular Medicine

John Radcliffe Hospital

Headington

Oxford, UK

\section{GREGORY GERMINO}

Department of Medicine

Johns Hopkins University School of Medicine

Baltimore, Maryland USA

\section{KathY KLINGer}

GREG LANDES

Integrated Genetics

The Genetic Reference Laboratory

One Mountain Road

Framingham, Massachusetts USA

JANET VAN ADELSBERG

Department of Medicine

College of Physicians \& Surgeons

Columbia University

New York, New York USA

1. The American PKD1 Consortium. Analysis of the genomic sequence for the autosomal dominant polycystic kidney disease (PKD1) gene predicts the presence of leucine-rich repeat. Hum. molec. Gen. (in the press).

2. van Adelsberg, J.S. \& Frank, D. The PKD1 gene produces a developmentally regulated protein in mesenchyme and vasculature. Nature Med. 1, 359-364, (1995).

3. The European Polycystic Kidney Disease Consortium. The polycystic kidney disease 1 gene encodes a $14 \mathrm{~kb}$ transcript and lies within a duplicated region on chromosome 16 . Cell 77, 881-894 (1994).

\section{Blood safety}

To the editor - In the news article "Making global blood safety a priority" (Nature Medicine 1, 7; 1995) there was a map showing the percentage of donated blood screened for HIV in 1992. The data for Croatia $(0-50 \%)$ are not correct because in Croatia $100 \%$ of donors have been regularly tested at each donation for anti-HIV since 1987 . There is no transfusion-associated HIV infection, and only $3 \%$ of hemophiliacs were HIV infected by imported coagulation factor concentrates. Because of that we consider transfusion therapy in Croatia very safe.

\section{DAMIR GRGICEVIC}

Croatian Institute for Transfusion Medicine

Zagreb, Croatia

To the editor - In the article "Making global blood safety a priority", it was stated that in developing countries testing of donated blood for HIV was insufficient or of poor quality. There was a map illustrating the situation in 1992. Slovenia was presented as part of the former Yugoslavia and the percentage of donated blood screened for HIV was shown as comparable to that of developing countries. We would like to point out that the situation in Slovenia is in fact very different.

In January 1986, mandatory screening for anti-HIV was implemented. Only blood units found non-reactive for antiHIV were released for transfusion or plasma fractionation. Each single unit is also individually tested for syphilis, $\mathrm{HBs} A \mathrm{~g}$ and anti-HCV, using the latest test assays produced by leading manufacturers. Furthermore, all blood donations are voluntary and non-renumerated; screening results are recorded on computer; and all work is performed on appropriate premises, by well-trained personnel and according to standards based on AABB regulations.

In conclusion, it can be stated that blood transfusion in Slovenia is as safe as in any West European country.

\section{Marjeta Potocnik \\ Blood Transfusion Centre of Slovenia Ljubljana, Slovenia}

Reply - The map reflects statistics provided by the World Health Organization. 